\title{
A Novel Antibiotic-Producing Actinomadura, Actinomadura kijaniata sp. nov.
}

\author{
ANN C. HORAN AND BEVERLY C. BRODSKY \\ Schering-Plough Corporation, Bloomfield, New Jersey 07003
}

\begin{abstract}
A new species of Actinomadura, Actinomadura kijaniata, was isolated from African soil. This organism differs from other species of Actinomadura in that it forms deep green vegetative mycelia and white, curled aerial mycelia that fragment into long chains of smooth-walled, elliptical spores and produces a complex of novel acid enol antibiotics. Whole cells contain meso-diaminopimelic acid and madurose but lack nitrogenous phospholipids. This species can utilize a wide variety of carbohydrates, grow in the presence of numerous antibiotics, and actively hydrolyze many organic compounds. The type strain of A. kijaniata is SCC 1256 (= ATCC 31588).
\end{abstract}

During an examination of antibiotic-producing Actinomycetales isolated from soil, we observed that one strain (SCC 1256) produced a pigment that was distinct from the pigments produced by all of the other strains which we had studied. On agar surfaces, white aerial mycelia and deep green vegetative mycelia were formed; in broth, light to dark green mycelia and soluble pigments were formed. Strain SCC 1256 was particularly interesting because it produced a complex of novel acid enol antibiotics, the major component of which was designated kijanimicin (26). In this paper we identify and classify this kijanimicinproducing strain.

\section{MATERIALS AND METHODS}

Bacterial strains. Table 1 lists the strains of Actinomadura used in this study. Strain SCC 1256 was isolated from a soil sample collected in Kenya, Africa. A culture of this strain has been deposited in the American Type Culture Collection (ATCC), Rockville, Md., where it has been assigned the number ATCC 31588.

Strain maintenance. The source materials used for this study were freeze-dried preparations of pure cultures. The contents of each vial were suspended in 10 $\mathrm{ml}$ of liquid medium (ATCC medium 172) (1) in a 25$\mathrm{mm}$ tube stoppered with a Morton closure. Broth suspensions were incubated at $30^{\circ} \mathrm{C}$ on a rotary shaker (model G-52; New Brunswick Scientific Co.) at 250 rpm for 3 to 4 days; then $5 \mathrm{ml}$ of each culture was transferred into $50 \mathrm{ml}$ of fresh medium in a $250-\mathrm{ml}$ Erlenmeyer flask stoppered with cotton and incubated as described above. The growth was harvested after 3 to 4 days, and $5-\mathrm{ml}$ quantities of the resulting biomass were dispensed aseptically into sterile screw-capped vials $(17$ by $60 \mathrm{~mm})$ and stored at $-18^{\circ} \mathrm{C}$.

Preparation of inocula. A 1-ml sample of thawed cell suspension was used to inoculate each broth tube, as described above. After 3 days at $30^{\circ} \mathrm{C}$, the cells were harvested by centrifugation, washed twice with sterile distilled water, and suspended in water to three times the packed-cell volume. The resulting washed suspen- sions were used as inocula for the tests described below.

TABLE 1. Strains of Actinomadura used in this study $^{a}$

\begin{tabular}{|c|c|c|c|}
\hline \multirow{2}{*}{$\begin{array}{c}\text { Laboratory } \\
\text { no. }\end{array}$} & \multicolumn{2}{|c|}{ Received as: } & \multirow{2}{*}{ Source } \\
\hline & Species & Strain & \\
\hline $\begin{array}{l}\text { SCC } 1256 \\
\text { A } 27887\end{array}$ & $\begin{array}{l}\text { Original isolate } \\
\text { Actinomadura } \\
\text { citrea }\end{array}$ & $\begin{array}{l}13-363 \\
\text { ATCC } 27887 \\
\text { (type) }\end{array}$ & $\begin{array}{l}\text { Soil } \\
\text { ATCC }\end{array}$ \\
\hline A 29533 & $\begin{array}{l}\text { Actinomadura } \\
\text { flava }\end{array}$ & $\begin{array}{c}\text { ATCC } 29533 \\
\text { (type) }\end{array}$ & ATCC \\
\hline A 27295 & $\begin{array}{l}\text { Actinomadura } \\
\text { helvata }\end{array}$ & $\begin{array}{l}\text { ATCC } 27295 \\
\text { (type) }\end{array}$ & ATCC \\
\hline A 31286 & $\begin{array}{l}\text { "Actinomadura } \\
\text { macra" }\end{array}$ & $\begin{array}{c}\text { ATCC } 31286 \\
\text { (type) }\end{array}$ & ATCC \\
\hline SCC 908 & $\begin{array}{l}\text { "Nocardia } \\
\text { madurae" }\end{array}$ & IMRU $777(7)$ & IMRU' \\
\hline A 27888 & $\begin{array}{r}\text { Actinomadura } \\
\text { malachitica }\end{array}$ & $\begin{array}{l}\text { ATCC } 27888 \\
\text { (type) }\end{array}$ & ATCC \\
\hline SCC 918 & $\begin{array}{l}\text { "Nocardia } \\
\text { pelletieri" }\end{array}$ & $\begin{array}{l}\text { NCTC } 4162 \\
\text { (type) }\end{array}$ & IMRU \\
\hline A 27296 & $\begin{array}{l}\text { Actinomadura } \\
\text { pusilla }\end{array}$ & $\begin{array}{l}\text { ATCC } 27296 \\
\text { (type) }\end{array}$ & ATCC \\
\hline A 27297 & $\begin{array}{l}\text { Actinomadura } \\
\text { roseoviolacea }\end{array}$ & $\begin{array}{c}\text { ATCC } 27297 \\
\text { (type) }\end{array}$ & ATCC \\
\hline A 27031 & $\begin{array}{l}\text { "Micromonospora } \\
\text { rubra" }\end{array}$ & $\begin{array}{c}\text { ATCC } 27031 \\
\text { (type) }\end{array}$ & ATCC \\
\hline A 27298 & $\begin{array}{l}\text { Actinomadura } \\
\text { spadix }\end{array}$ & $\begin{array}{l}\text { ATCC } 27298 \\
\text { (type) }\end{array}$ & ATCC \\
\hline A 27299 & $\begin{array}{l}\text { Actinomadura } \\
\text { verrucosospora }\end{array}$ & $\begin{array}{c}\text { ATCC } 27299 \\
\text { (type) }\end{array}$ & ATCC \\
\hline
\end{tabular}

${ }^{a}$ Of the 24 Actinomadura species on the Approved Lists of Bacterial Names (23), only the species listed were available from the ATCC.

${ }^{b}$ Names in quotation marks are not on the Approved Lists of Bacterial Names (23) and were not validly published as of 1 January 1980 .

c IMRU, Institute of Microbiology, Rutgers University Busch Campus, Piscataway, N.J. 


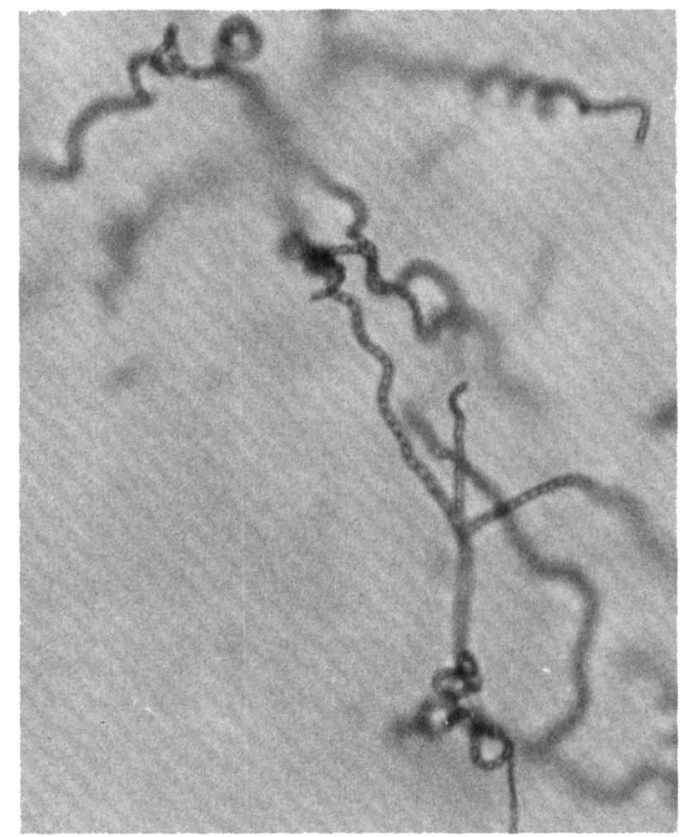

FIG. 1. Aerial mycelium of strain SCC 1256 fragmenting into chains of elliptical spores on water agar. $\times 450$.

Morphological observations. Washed cells were inoculated onto the surfaces of the following media in petri dishes: YD agar $(10 \mathrm{~g}$ of yeast extract, $10 \mathrm{~g}$ of dextrose, and $15 \mathrm{~g}$ of agar in $1,000 \mathrm{ml}$ of tap water, $\mathrm{pH}$ $7.0)$; water agar (15 $\mathrm{g}$ of agar in $1,000 \mathrm{ml}$ of tap water, $\mathrm{pH} 7.0)$; and half-strength starch agar ( $2.5 \mathrm{~g}$ of yeast extract, $5.0 \mathrm{~g}$ of potato starch, and $15 \mathrm{~g}$ of agar in 1,000 $\mathrm{ml}$ of distilled water, $\mathrm{pH} 7.0$ ). The inoculated plates were incubated at $30^{\circ} \mathrm{C}$ for $5,10,15$, and 20 days and examined after each time period directly under a microscope. Representative plates of strain SCC 1256 were flooded with sterile tap water, the surface growth was gently scraped, and samples were examined microscopically for motile spores. Spores were examined with an electron microscope by using the procedures of Luedemann and Casmer (17).

Chemical analysis of whole cells. The presence and form of diaminopimelic acid and the presence of carbohydrates in whole-cell hydrolysates were determined by the methods of Becker et al. (2) and Lechevalier (14). Phospholipids were analyzed by the procedure of Lechavalier et al. (15).

Growth characteristics. Strain SCC 1256 was cultivated on standard media as described by Shirling and Gottlieb (22) and Waksman (27). Media in plates were inoculated and incubated for 14 to 21 days at $30^{\circ} \mathrm{C}$. Each color designation assigned to the vegetative mycelium pigments consisted of a color name (25) and a color chip number (3).

Carbohydrate utilization. Carbohydrate utilization was determined by the procedure of Luedemann and Brodsky (16).

Decomposition of organic compounds. The procedures of Gordon et al. (8) and Goodfellow (5) were used to determine the decomposition of organic compounds. Hydrolysis of deoxyribonucleic acid was measured by the method of Jeffries et al. (10).

Decomposition of urea and allantoin. The decomposition of urea and the decomposition of allantoin were determined by the procedures of Gordon et al. (8) and Kurup and Schmitt (11), respectively.

Production of lactamase. Lactamase was detected by method B of Schwartz and Schwartz (21).

Temperature relationships. We tested the ability of strain SCC 1256 to grow at $28,35,40$, and $45^{\circ} \mathrm{C}$ and to survive at $50^{\circ} \mathrm{C}$ on ATCC medium 172 by using the techniques of Gordon et al. (8).

Antibiotic susceptibility. The amount of each antibiotic that resulted in a concentration (based on activity) of $1,000 \mu \mathrm{g} / \mathrm{ml}$ was dissolved in the appropriate solvent, diluted in sterile distilled water to a concentration of $500 \mu \mathrm{g} / \mathrm{ml}$, and filter sterilized. Each antibiotic was incorporated into YD agar to a final concentration of $50 \mu \mathrm{g} / \mathrm{ml}$ and then dispensed into sterile petri dishes. Inoculated plates were incubated at $30^{\circ} \mathrm{C}$ and examined for growth after 5, 7, and 14 days.

\section{RESULTS AND DISCUSSION}

Morphological observations. On both YD agar and water agar, abundant aerial mycelia which fragment into long chains of eliptical spores $(10$ or more) approximately 1.0 to $1.5 \mu \mathrm{m}$ in diameter by 1.5 to $2.0 \mu \mathrm{m}$ long (Fig. 1) are formed. Electron microscopic observation indicated that the spores are smooth walled. Aerial mycelia occur as long, open spirals. Motile spores do not occur. The vegetative mycelia form abundant branches and also appear to fragment into chains of spores.

Whole-cell analysis. Hydrolyzed whole cells contain the meso isomer of diaminopimelic acid, along with a trace of the L-isomer. Madurose is the characteristic sugar component. A type PI phospholipid pattern, characteristic of Actinomadura, was found.

Growth characteristics. Table 2 shows the macroscopic appearance of strain SCC 1256 on various descriptive media. This strain grows well on most organic media. The vegetative mycelium colors range from tan to dark green; shades of green are characteristic. Abundant white aerial mycelia are formed on ISP no. 7 agar and starch agar. Gray, brown, and green diffusible pigments are formed on several media.

Carbohydrate utilization and physiological properties. Table 3 shows the carbohydrate utilization and physiological properties of strain SCC 1256. The positive properties include utilization of adonitol, D-arabinose, L-arabinose, fructose, L-fucose, galactose, glucose, glycerol, inositol, maltose, mannose, rhamnose, ribose, sucrose, trehalose, and D-xylose; methyl- $\beta$-Dglucopyranoside is utilized and a distinctive green diffusible pigment is formed. Strain SCC 1256 is capable of hydrolyzing all of the com- 
TABLE 2. Growth characteristics of strain SCC 1256 on various media

\begin{tabular}{|c|c|c|c|c|c|}
\hline Medium & Growth & $\begin{array}{c}\text { Surface } \\
\text { characteristics }\end{array}$ & Aerial mycelium & $\begin{array}{l}\text { Diffusible } \\
\text { pigments }\end{array}$ & Color of growth ${ }^{a}$ \\
\hline Bennett agar &,+++ good & Raised, folded & $\begin{array}{l}\text { Present } \\
\text { (sparse, } \\
\text { white) }\end{array}$ & Absent & g 22 li (pine green) \\
\hline $\begin{array}{l}\text { Czapek sucrose } \\
\text { agar }\end{array}$ & +++ , good & Ribbon-like & Absent & Absent & $\begin{array}{l}\text { g } 22 \text { n (dark pine } \\
\text { green) }\end{array}$ \\
\hline $\begin{array}{l}\text { Glucose asparagine } \\
\text { agar }\end{array}$ &,$+++ \operatorname{good}$ & Raised, folded & $\begin{array}{l}\text { Present (sparse } \\
\text { white } \\
\text { specks) }\end{array}$ & Absent & $\begin{array}{l}\text { g } 22 \text { n (dark pine } \\
\text { green) }\end{array}$ \\
\hline $\begin{array}{l}\text { Glycerol asparagine } \\
\text { agar }\end{array}$ &,$+++ \operatorname{good}$ & Flat, folded & Absent & $\begin{array}{l}\text { Gray, red- } \\
\text { brown }\end{array}$ & $\begin{array}{l}\text { Center, g } 19 \text { po } \\
\text { (dark laurel); } \\
\text { periphery, g } 6 \text { ie } \\
\text { (redwood) }\end{array}$ \\
\hline Nutrient agar &,+++ good & Raised, folded & Absent & $\begin{array}{l}\text { Faint dull } \\
\text { green }\end{array}$ & g 23 n (evergreen) \\
\hline Water agar & \pm , poor & Granular & Absent & Absent & $\begin{array}{l}\text { g } 24 \text { ge (dusty } \\
\text { green) }\end{array}$ \\
\hline $\begin{array}{l}\text { Yeast extract malt } \\
\text { extract agar (ISP } \\
\text { no. 2) }\end{array}$ &,$+++ \operatorname{good}$ & $\begin{array}{l}\text { Raised, hard, } \\
\text { folded }\end{array}$ & $\begin{array}{l}\text { Present (white } \\
\text { specks) }\end{array}$ & Absent & $\begin{array}{l}\text { Center, g } 21 \mathrm{nl} \\
\text { (dark jade } \\
\text { green); } \\
\text { periphery, g } 2 \mathrm{ec} \\
\text { (biscuit) }\end{array}$ \\
\hline $\begin{array}{l}\text { Potato dextrose } \\
\text { agar }\end{array}$ & ++ , moderate & $\begin{array}{l}\text { Flat to slightly } \\
\text { raised }\end{array}$ & Absent & Absent & g 2 ge (covert tan) \\
\hline Emerson agar & $\begin{array}{l}+ \text { to }++, \text { fair to } \\
\text { moderate }\end{array}$ & Flat, granular & Absent & Absent & g 22 ig (bayberry) \\
\hline NZA glucose agar &,$+++ \operatorname{good}$ & $\begin{array}{l}\text { Soft, compactly } \\
\text { folded }\end{array}$ & Absent & $\begin{array}{l}\text { Absent to } \\
\text { dark } \\
\text { brown }\end{array}$ & g 15 po (dark slate) \\
\hline $\begin{array}{l}\text { Yeast extract } \\
\text { glucose agar }\end{array}$ &,$+++ \operatorname{good}$ & $\begin{array}{l}\text { Raised, deeply } \\
\text { folded, hard } \\
\text { cracking }\end{array}$ & $\begin{array}{l}\text { Present (white } \\
\text { specks) }\end{array}$ & Absent & $\begin{array}{l}\text { Center, g } 22 \text { ig } \\
\text { (almond green); } \\
\text { periphery, g } 3 \text { ge } \\
\text { (camel) }\end{array}$ \\
\hline $\begin{array}{l}\text { Tomato paste } \\
\text { oatmeal agar }\end{array}$ &,+++ good & Flat, granular & $\begin{array}{l}\text { Present (white } \\
\text { specks) }\end{array}$ & Absent & $\begin{array}{l}\text { g } 11 / 2 \text { li (light olive } \\
\text { drab) }\end{array}$ \\
\hline $\begin{array}{l}\text { Starch agar } \\
\text { (Waksman no. } \\
\text { 21) }\end{array}$ & + , fair & Flat, granular & Absent & Absent & g 24 ig (sage green) \\
\hline $\begin{array}{l}\text { Calcium maleate } \\
\text { agar (Waksman } \\
\text { no. 7) }\end{array}$ & $\begin{array}{l}+ \text { to }++, \text { fair to } \\
\text { moderate }\end{array}$ & Plicate, soft & Absent & Absent & g 2 gc (bamboo) \\
\hline $\begin{array}{l}\text { Oatmeal agar (ISP } \\
\text { no. 3) }\end{array}$ & $\begin{array}{l}+ \text { to }++, \text { fair to } \\
\text { moderate }\end{array}$ & Flat, granular & $\begin{array}{l}\text { Present (white } \\
\text { specks) }\end{array}$ & Absent & $\begin{array}{l}\text { g } 22 \text { nl (dark pine } \\
\text { green) }\end{array}$ \\
\hline $\begin{array}{l}\text { Inorganic salts } \\
\text { starch agar (ISP } \\
\text { no. 4) }\end{array}$ &,+ fair & Flat, granular & Absent & Faint green & $\begin{array}{l}\text { Center, g } 23 \text { li } \\
\text { (slate green); } \\
\text { periphery, g } 4 \text { ge } \\
\text { (light fawn) }\end{array}$ \\
\hline Peptone iron agar & ++ , moderate & $\begin{array}{l}\text { Raised, } \\
\text { granular }\end{array}$ & $\begin{array}{l}\text { Present (white } \\
\text { specks) }\end{array}$ & Absent & g 2 ge (covert tan) \\
\hline $\begin{array}{l}\text { Casein agar } \\
\text { Tyrosine agar } \\
\text { (ISP no. 7) }\end{array}$ & $\begin{array}{l}++, \text { moderate } \\
+++, \text { good }\end{array}$ & $\begin{array}{l}\text { Flat, granular } \\
\text { Raised, folded }\end{array}$ & $\begin{array}{l}\text { Absent } \\
\text { Present } \\
\text { (abundant, } \\
\text { white) }\end{array}$ & $\begin{array}{l}\text { Absent } \\
\text { Absent }\end{array}$ & $\begin{array}{l}\text { g } 22 \text { ih (moss gray) } \\
\text { g } 5 \text { ih (lead gray) }\end{array}$ \\
\hline $\begin{array}{l}\text { Starch agar (yeast) } \\
\text { Calcium citrate } \\
\text { agar }\end{array}$ & $\begin{array}{l}+++, \text { good } \\
+, \text { fair }\end{array}$ & $\begin{array}{l}\text { Hard, folded } \\
\text { Flat, granular }\end{array}$ & $\begin{array}{l}\text { Present (white) } \\
\text { Absent }\end{array}$ & $\begin{array}{l}\text { Absent } \\
\text { Absent }\end{array}$ & $\begin{array}{l}\text { g } 23 \text { li (slate green) } \\
\text { g } 2 \text { li (covert } \\
\text { brown) }\end{array}$ \\
\hline $\begin{array}{r}\text { Gelatin agar } \\
\text { (McDade) }\end{array}$ & ++ , moderate & $\begin{array}{l}\text { Raised, } \\
\text { compactly } \\
\text { folded }\end{array}$ & Absent & Absent & $\begin{array}{l}\text { Center, g } 1 \text { po } \\
\text { (ebony); } \\
\text { periphery, g } 1 \text { fe } \\
\text { (greige) }\end{array}$ \\
\hline
\end{tabular}

\footnotetext{
${ }^{a}$ See references 3 and 25 .
} 
TABLE 3. Physiological properties of strain SCC 1256

\begin{tabular}{|c|c|c|c|}
\hline Test & Results & Test & Results \\
\hline \multicolumn{2}{|l|}{ Growth on carbohydrates } & Starch $\ldots \ldots \ldots \ldots \ldots \ldots \ldots$ & + (weak) \\
\hline 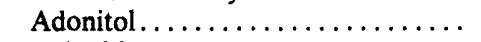 & +++ & Deoxyribonucleic acid ......... & + \\
\hline D-Arabinose $\ldots \ldots \ldots \ldots \ldots \ldots$ & +++ & Gelatin $\ldots \ldots \ldots \ldots \ldots \ldots \ldots$ & + \\
\hline L-Arabinose. . . . . . . . . . & +++ & Elastin $\ldots \ldots \ldots \ldots \ldots \ldots \ldots$ & + \\
\hline 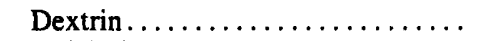 & +++ & 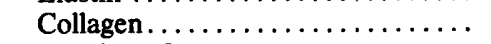 & + \\
\hline Dulcitol $\ldots \ldots \ldots \ldots \ldots \ldots \ldots$ & - & Formation of: & \\
\hline Erythritol.................. & - & Urease $\ldots \ldots \ldots \ldots \ldots \ldots \ldots$ & + \\
\hline Fructose $\ldots \ldots \ldots \ldots \ldots \ldots \ldots$ & +++ & Allantoinase $\ldots \ldots \ldots \ldots \ldots \ldots$ & + \\
\hline L-Fucose $\ldots \ldots \ldots \ldots \ldots \ldots \ldots$ & +++ & Lactamase..$\ldots \ldots \ldots \ldots \ldots$ & + \\
\hline 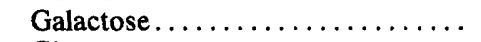 & $++t$ & Growth at: & \\
\hline Glucose .................. & +++ & $28^{\circ} \mathrm{C} \ldots \ldots \ldots \ldots \ldots \ldots \ldots \ldots \ldots \ldots \ldots \ldots \ldots$ & + \\
\hline$\alpha$-methyl-D-Glucoside $\ldots \ldots \ldots \ldots$ & - & 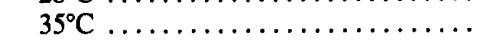 & + \\
\hline \multirow[t]{2}{*}{ Methyl- $\beta$-D-glucopyranoside ..... } & +++ & 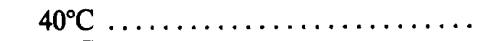 & + \\
\hline & $(\text { green DFP })^{a}$ & 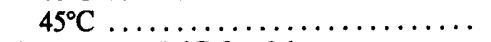 & + \\
\hline Glycerol ................ & +++ & Survival at $50^{\circ} \mathrm{C}$ for $8 \mathrm{~h} \ldots \ldots \ldots$ & + \\
\hline Inositol.$\ldots \ldots \ldots \ldots \ldots \ldots \ldots$ & $+t+$ & Growth in the presence of: ${ }^{b}$ & \\
\hline Inulin $\ldots \ldots \ldots \ldots \ldots \ldots \ldots$ & - & 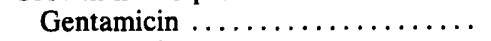 & + \\
\hline Lactose ................... & - & Kanamycin $\ldots \ldots \ldots \ldots \ldots \ldots$ & + \\
\hline Maltose $\ldots \ldots \ldots \ldots \ldots \ldots \ldots$ & +++ & Neomycin $\ldots \ldots \ldots \ldots \ldots \ldots$ & + \\
\hline Mannitol................... & - & Paromomycin $\ldots \ldots \ldots \ldots \ldots \ldots$ & + \\
\hline 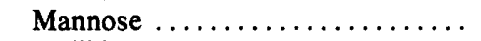 & +++ & Sisomicin.$\ldots \ldots \ldots \ldots \ldots$ & + \\
\hline Melibiose.................. & - & Streptomycin............... & + \\
\hline Melizitose ................. & - & Erythromycin ............. & + \\
\hline 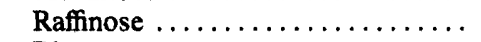 & - & 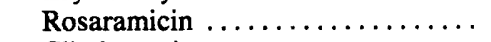 & - \\
\hline Rhamnose.$\ldots \ldots \ldots \ldots \ldots \ldots$ & +++ & Clindamycin $\ldots \ldots \ldots \ldots \ldots \ldots$ & + \\
\hline Ribose..$\ldots \ldots \ldots \ldots \ldots \ldots$ & +++ & Lincomycin ............... & + \\
\hline Sucrose...$\ldots \ldots \ldots \ldots \ldots \ldots$ & +++ & Tetracycline.$\ldots \ldots \ldots \ldots \ldots \ldots$ & + \\
\hline Trehalose................... & +++ & Everninomicin $\ldots \ldots \ldots \ldots \ldots \ldots$ & + \\
\hline D-Xylose $\ldots \ldots \ldots \ldots \ldots \ldots$ & +++ & Rifamycin $\ldots \ldots \ldots \ldots \ldots \ldots$ & + \\
\hline Hydrolysis of: & & Penicillin G . ............... & + \\
\hline Adenine $\ldots \ldots \ldots \ldots \ldots \ldots \ldots$ & + (weak) & Cephalothin ................ & + \\
\hline Hypoxanthine ............... & + & 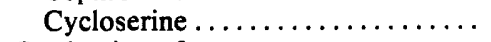 & + \\
\hline Tyrosine .................. & + & Production of: & \\
\hline Xanthine $\ldots \ldots \ldots \ldots \ldots \ldots \ldots$ & + & $\mathrm{H}_{2} \mathrm{~S} \ldots \ldots \ldots \ldots \ldots \ldots \ldots \ldots \ldots \ldots \ldots \ldots \ldots \ldots$ & - \\
\hline 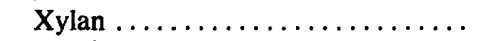 & + & Melanin..$\ldots \ldots \ldots \ldots \ldots \ldots$ & - \\
\hline Casein.................... & + & & \\
\hline
\end{tabular}

${ }^{a}$ DFP, Diffusible pigment.

${ }^{b}$ All antibiotics were tested at a concentration of $50 \mu \mathrm{g} / \mathrm{ml}$.

pounds tested; however, the hydrolyses of starch and adenine are weak. Urea and allantoin are degraded, growth occurs at $45^{\circ} \mathrm{C}$, the strain survives at $50^{\circ} \mathrm{C}$ for $8 \mathrm{~h}$, growth occurs in the presence of most of the antibiotics tested, and lactamase is formed. Strain SCC 1256 is unable to utilize dulcitol, erythritol, $\alpha$-methyl-D-glucoside, inulin, lactose, mannitol, melibiose, melizitose, or raffinose, to grow in the presence of rosaramicin, and to form hydrogen sulfide and melanin.

Identity of strain SCC 1256. The presence of meso-diaminopimelic acid and madurose as characteristic whole-cell components, a type PI phospholipid pattern, and the formation of aerial mycelia with long spore chains identify this strain as a member of the genus Actinomadura Lechevalier and Lechevalier (13). Table 4 compares the whole-cell data and differentiating morphological and physiological (6) characteristics of the strains listed in Table 1 with the data obtained for SCC 1256. Of the strains used in this study and the species of Actinomadura described in the literature, none shares with SCC 1256 the combination of deep green vegetative mycelia, white to green aerial mycelia, long spore chains with smooth spores, the ability to hydrolyze xanthine, the ability to utilize methyl$\beta$-D-glucoside, and the ability to produce kijanimicin.

Our data suggest that strain SCC 1256 represents a new, distinct antibiotic-producing species of Actinomadura, for which the name Actinomadura kijaniata is proposed. The specific epithet is derived from kijani, the Swahili word for green. The type strain is SCC 1256 (= ATCC 31588). Since at present there has been only one strain identified as belonging to this species, (the 
TABLE 4. Morphological and chemical characteristics of ATCC Actinomadura species and strain SCC 1256

\begin{tabular}{|c|c|c|c|c|c|c|c|c|c|c|}
\hline \multirow[b]{2}{*}{ Taxon } & \multirow[b]{2}{*}{$\begin{array}{l}\text { Refer- } \\
\text { ence(s) }\end{array}$} & \multirow[b]{2}{*}{ Spore chains } & \multirow[b]{2}{*}{$\begin{array}{l}\text { Spore } \\
\text { surfaces }\end{array}$} & \multirow[b]{2}{*}{$\begin{array}{l}\text { Aerial mycelium } \\
\text { color }\end{array}$} & \multirow[b]{2}{*}{$\begin{array}{c}\text { Vegetative } \\
\text { mycelium color }\end{array}$} & \multirow{2}{*}{$\begin{array}{c}\text { meso- } \\
\text { Diamino- } \\
\text { pimelic } \\
\text { acid and } \\
\text { madurose }\end{array}$} & \multirow[b]{2}{*}{$\begin{array}{l}\text { Antibiotic } \\
\text { activity }\end{array}$} & \multirow[b]{2}{*}{$\begin{array}{l}\text { Hydrolysis } \\
\text { of xanthine }\end{array}$} & \multicolumn{2}{|c|}{ Utilization of: } \\
\hline & & & & & & & & & $\begin{array}{l}\text { Methyl- } \beta- \\
\text { D-gluco- } \\
\text { side }\end{array}$ & Mannitol \\
\hline SCC 1256 & & $\begin{array}{l}\text { Flexous spirals, } \\
\text { long }\end{array}$ & Smooth & $\begin{array}{l}\text { White to pale } \\
\text { green }\end{array}$ & Dark green & + & + & + & + & - \\
\hline $\begin{array}{l}\text { Actinomadura citrea } \\
\text { ATCC } 27887\end{array}$ & 12 & $\begin{array}{l}\text { Straight to hooked, } \\
\text { short }\end{array}$ & Uneven & Yellow-blue & Lemon yellow & + & - & - & - & + \\
\hline $\begin{array}{l}\text { A. flava } \\
\text { ATCC } 29533\end{array}$ & 4 & Straight, long & Smooth & Rarely formed & $\begin{array}{l}\text { Lemon yellow, } \\
\text { yellow- } \\
\text { brown }\end{array}$ & + & + & - & - & + \\
\hline $\begin{array}{l}\text { A. helvata } \\
\text { ATCC } 27295\end{array}$ & 19,20 & $\begin{array}{l}\text { Closed spirals, } \\
\text { short }\end{array}$ & Smooth & White to pink & Yellow-brown & + & - & - & - & + \\
\hline $\begin{array}{l}\text { "A. macra" } \\
\text { ATCC } 31286^{a}\end{array}$ & 9 & $\begin{array}{l}\text { Straight to flexous, } \\
\text { short }\end{array}$ & Smooth & Grayish & Cream to gray & + & + & - & - & - \\
\hline $\begin{array}{l}\text { A. madurae } \\
\text { IMRU } 777\end{array}$ & 7 & $\begin{array}{l}\text { Curls to hooks, } \\
\text { short }\end{array}$ & Smooth & $\begin{array}{l}\text { Rarely formed, } \\
\text { white-pink }\end{array}$ & Pink to red & + & + & - & - & + \\
\hline $\begin{array}{r}\text { A. malachitica } \\
\text { ATCC } 27888\end{array}$ & 12 & $\begin{array}{l}\text { Loose spirals, } \\
\text { short }\end{array}$ & Smooth & $\begin{array}{l}\text { Rarely formed, } \\
\text { pale green }\end{array}$ & Cream & + & - & - & - & + \\
\hline $\begin{array}{l}\text { A. pelletieri } \\
\text { NCTC } 4162\end{array}$ & 7,13 & $\begin{array}{l}\text { Curls to hooks, } \\
\text { short }\end{array}$ & Smooth & $\begin{array}{l}\text { Rarely formed, } \\
\text { white to pink }\end{array}$ & Pink to red & + & + & - & - & - \\
\hline $\begin{array}{l}\text { A. pusilla } \\
\text { ATCC } 27296\end{array}$ & 19,20 & $\begin{array}{l}\text { Closed spirals, } \\
\text { short }\end{array}$ & Smooth & White to pink & $\begin{array}{c}\text { Brownish gray, } \\
\text { blue-black }\end{array}$ & & + & - & + & - \\
\hline $\begin{array}{l}\text { A. roseoviolacea } \\
\text { ATCC } 27297\end{array}$ & 19,20 & $\begin{array}{l}\text { Hooks to closed } \\
\text { spirals, short }\end{array}$ & Smooth & White to pink & Red to violet & + & - & - & - & + \\
\hline $\begin{array}{l}\text { A. rubra } \\
\text { ATCC } 27031\end{array}$ & 18,24 & $\begin{array}{l}\text { Hooks to spirals, } \\
\text { short }\end{array}$ & $\begin{array}{l}\text { Smooth to } \\
\text { uneven }\end{array}$ & $\begin{array}{l}\text { Rarely formed, } \\
\text { white to pink }\end{array}$ & Brick red & + & + & - & - & + \\
\hline $\begin{array}{l}\text { A. spadix } \\
\text { ATCC } 27298\end{array}$ & 19,20 & $\begin{array}{l}\text { Hooks to closed } \\
\text { spirals, short }\end{array}$ & Smooth & Grayish & Gray-brown & + & - & - & - & + \\
\hline $\begin{array}{l}\text { A. verrucosospora } \\
\text { ATCC } 27299\end{array}$ & 19,20 & Hooks to spirals & Uneven & Grayish blue & Pink & + & $--^{b}$ & - & - & + \\
\hline
\end{tabular}

${ }^{a}$ Name not on the Approved Lists of Bacterial Names (23) and not validly published as of 1 January 1980.

${ }^{b}$ ATCC 31466, a strain identified as $A$. verrucosospora has been reported to produce a new polycylic antibiotic (U.S. patent 4,195,079). 
type strain), the description presented above applies to both the species and the type strain.

\section{ACKNOWLEDGMENTS}

We thank Mary P. Lechevalier, Waksman Institute, Rutgers University, for the lipid analysis and the interpretation of the results.

\section{REPRINT REQUESTS}

Address reprint requests to: Dr. Ann C. Horan, ScheringPlough Corporation, Bloomfield, NJ 07003.

\section{LITERATURE CITED}

1. American Type Culture Collection. 1980. Catalogue of strains I, 14th ed. American Type Culture Collection, Rockville, Md.

2. Becker, B., M. P. Lechevalier, R. E. Gordon, and H. A. Lechevalier. 1964. Rapid differentiation between Nocardia and Streptomyces by paper chromatography of whole-cell hydrolysates. Appl. Microbiol. 12:421-423.

3. Container Corporation of America. 1958. Color harmony manual, 4 th ed. Container Corporation of America, Chicago.

4. Gause, G. F., T. S. Maksimova, O. L. Olkhovatova, M. A. Sveshnikova, G. V. Kochetkova, and G. B. Ilchenko. 1974. Production of madumycin, an antibacterial antibiotic, by Actinomadura flava sp. nov. Antibiotiki (Moscow) 9:771775.

5. Goodfellow, M. 1971. Numerical taxonomy of some nocardioform bacteria. J. Gen. Microbiol. 69:33-80.

6. Goodfellow, M., G. Alderson, and J. Lacey. 1979. Numerical taxonomy of Actinomadura and related actinomycetes. J. Gen. Microbiol. 112:95-111.

7. Gordon, R. E. 1966. Some criteria for the recognition of Nocardia madurae (Vincent) Blanchard. J. Gen. Microbiol. 45:355-364.

8. Gordon, R. E., D. A. Barnett, J. E. Handerhan, and C. H. Pang. 1974. Nocardia coeliaca, Nocardia autotrophica, and the nocardin strain. Int. J. Syst. Bacteriol. 24:54-63.

9. Huang, L. H. 1980 . Actinomadura macra sp. nov., the producer of antibiotics CP-47,433 and CP-47,434. Int. J. Syst. Bacteriol. 30:565-568.

10. Jefiries, C. D., D. F. Holtman, and D. G. Guse. 1957. Rapid method for determining the activity of microorganisms on nucleic acids. J. Bacteriol. 73:590-591.

11. Kurup, P. V., and J. A. Schmitt. 1973. Numerical taxonomy of Nocardia. Can. J. Microbiol. 19:1035-1048.

12. Lavrova, N. V., T. P. Preobrazhenskaya, and M. A. Sveshnikove. 1972. Isolation of soil actinomycetes on selective media with rubomycin. Antibiotiki (Moscow) 20:404-409.
13. Lechevaller, H. A., and M. P. Lechevalier. 1970. A critical evaluation of the genera of aerobic actinomycetes, p. 393405. In H. Prauser (ed.), The Actinomycetales. Gustav Fischer Verlag, Jena.

14. Lechevalier, M. P. 1968. Identification of aerobic actinomycetes of clinical importance. J. Lab. Clin. Med. 71:934-944.

15. Lechevalier, M. P., C. DeBievre, and H. A. Lechevalier. 1977. Chemotaxonomy of aerobic actinomycetes: phospholipid composition. Biochem. Syst. Ecol. 5:249-260.

16. Luedemann, G. M., and B. Brodsky. 1965. Micromonospora carbonacea sp. n., an everninomicin-producing organism, p. 47-52. Antimicrob. Agents Chemother. 1964.

17. Luedemann, G. M., and C. J. Casmer. 1973. Electron microscope study of whole mounts and thin sections of Micromonospora chalcea ATCC 12452. Int. J. Syst. Bacteriol. 21:240-247.

18. Meyer, J., and M. Sveshnikova. 1974. Micromonospora rubra Sveshnikova et al. = Actinomadura rubra comb. nov. Z. Allg. Mikrobiol. 14:167-170.

19. Nonomura, H. 1974. Key for the classification and identification of species of rare actinomycetes isolated from soils in Japan. J. Ferm. Technol. 52:71-77.

20. Nonomura, H., and Y. Ohara. 1971. Distribution of actinomycetes in soil. XI. Some new species of the genus Actinomadura Lechevalier et at. J. Ferm. Technol. 49:904-912.

21. Schwartz, J. L., and S. P. Schwartz. 1979. Production of B-lactamase by non-Streptomyces Actinomycetales. Antimicrob. Agents Chemother. 15:123-125.

22. Shirling, E. B., and D. Gottlieb. 1966. Method for characterization of Streptomyces species. Int. J. Syst. Bacteriol. 16:313-340.

23. Skerman, V. B. D., V. McGowan, and P. H. A. Sneath (ed.). 1980. Approved lists of bacterial names. Int. J. Syst. Bacteriol. 30:225-420.

24. Sveshnikova, M. A., T. S. Maksimova, and E. S. Kudrina. 1969. The species of the genus Micromonospora Orskov, 1923, and their taxonomy. Mikrobiologiya 38:883-893.

25. Taylor, H. D., L. Knoche, and W. C. Granville. 1950. Descriptive color names dictionary. Container Corporation of America, Chicago.

26. Waitz, J. A., A. C. Horan, M. Kalyanpur, B. K. Lee, D. Loebenberg, J. A. Marquez, G. Miller, and M. G. Patel. 1981. Kijanimicin (Sch 25663), a novel antibiotic produced by Actinomadura kijaniata SCC 1256 . Fermentation, isolation, characterization and biological properties. J. Antibiot. 34:1101-1106.

27. Waksman, S. A. 1961 . The actinomycetes, vol. 2. The Williams \& Wilkins Co., Baltimore. 